\title{
The effect of rosemary extract and omega-3 unsaturated fatty acids on the properties of gels made from the flesh of mackerel (Scomber scombrus) by high pressure and heat treatments
}

\author{
M. PÉREZ-MATEOS ${ }^{(a)}$, M.C. GÓMEZ-GUILLÉN $^{*}{ }^{(a)}$, J.L. HURTADO $^{(a)}$, MT. \\ SOLAS ${ }^{(b)}$ and P. MONTERO ${ }^{(a)}$
}

(a) Instituto del Frío (CSIC), Dpto. Ciencia y Tecnología de Carnes y Pescados Ciudad Universitaria s / n, E28040 Madrid, Spain. Fax (34) 9154936.27

(b) Departamento de Biología Celular, Facultad de Ciencias Biológicas, Universidad Complutense de Madrid, E28040 Madrid, Spain cgomez@if.csic.es (author to whom correspondence should be addressed)

Key words: rosemary, omega-3, gelation, high pressure, mince, mackerel Running title: high pressure/thermal gelling mince - additives 


\begin{abstract}
Mackerel mince gels fortified with omega-3 and rosemary extract were studied in connection with high pressure / thermal treatments. Elasticity and breaking deformation were significantly higher in pressure-induced lots $\left(300 \mathrm{MPa}, 25^{\circ} \mathrm{C}, 15\right.$ min), while hardness was considerably lower. For gels without ingredients the fraction solubilised with $8 \mathrm{M}$ urea and $2 \% \beta$-mercaptoethanol was larger in the pressurised samples. SEM showed that pressure-induced gels generally presented a structure more compacted than heat-induced gels. The high pressure activated lipid oxidation, the antioxidant effect of rosemary being evident in all samples.
\end{abstract}




\section{INTRODUCTION}

One of the main factors influencing seafood consumption is its recognised nutritional qualities, especially the heath effects of omega-3 unsaturated fatty acids. In recent years there has also been increased interest in the consumption of restructured fish mince products: however, the mincing process involves washing where a part of the fat is removed. We are therefore interested in fortifying gels with omega-3 in the form of purified fish oil. Due to the presence of lipids - inherent and added - antioxidants are required to stabilise the product. Antioxidants are possibly the most efficient and economical means of preventing oxidation. Several synthetic phenolic antioxidants have been successfully used in restructured meats and fish products (Chastain et al. 1982; Crackel et al., 1988; Montero et al., 1996). However, consumers are becoming increasingly concerned about synthetic chemicals in foods and are interested in the use of natural products. Many spices and herbs have been shown to impart an antioxidant effect in food systems, and rosemary is among those with the highest activity (Liu et al., 1992). The antioxidant properties of spices are related to their phenolic contents, and therefore their antioxidant action is similar to that of synthetic phenolic antioxidants. However, the utilisation of spices and herbs in meat (Liu et al., 1992) and fish mince (Pérez-Mateos et al., 2001) is limited by sensory considerations. Some of the compounds in rosemary extract have a strong odour and bitter taste, so that there is particular interest in the antioxidant activity of low-odour, low-flavour rosemary extract and in the limiting quantity in each product (Duxbury, 1989; Liu et al., 1992). In several restructured meats, such as beef steaks (Angelo et al., 1990; Stoick et al., 1991), turkey sausages (Barbut et al., 1985) and chicken nuggets (Lai et al., 1991), it has been observed that rosemary extract possesses antioxidant activity comparable with a commercial blend of $\mathrm{BHA} / \mathrm{BHT}$. There have been a few studies on the antioxidant effect of rosemary in restructured meat but hardly any in meat gels. Most gels are formed by heating, and the antioxidant activity can be affected. Moreover, there is not much information about restructured products fortified with lipids. 
The texture of gels may also be affected because rheological properties can be very sensitive to the addition of any ingredients. This effect may differ depending on whether the gel-making process is the traditional one like thermal treatment or a combination of heat and high pressure. In this connection Buttler \& Larick (1993) observed the effect of antioxidants in heat-induced low-fat beef gels and the behaviour of shear stress and shear strain in the gel. They concluded that there were differences in oxidised flavour and beef flavour due to antioxidant treatment and that the use of antioxidants appeared to improve the sensory characteristics and oxidative stability of heat-induced beef gels. Shear stress and shear strain, measured by torsion test, were not significantly affected by antioxidant treatment. However, Bakir et al. (1994a) found that the addition of an antioxidant mixture to mackerel mince gave gels with higher true strain and lower stress values. In a study of fortification of crab analogue product with omega-3, Pérez-Mateos et al. (2001) observed a slight antioxidant effect of rosemary immediately after preparation of the heat gel in samples containing menhaden oil, but they found no additional stabilisation during storage. However, samples made with purified fish oil (omega-3) were quite stable overall. As regards texture, heat gels were not affected by the addition of oil but were improved by rosemary and green tea antioxidants. It is known that high pressure stabilises the antioxidant effect of different compounds more than heat treatment, and also that it is more effective when the antioxidants are pressurised (Messens et al., 1997). However, there are no studies on the behaviour of omega-3 and natural antioxidants, like rosemary extract, in muscle (fish/meat) gels induced by high pressure/heat treatment. Assuming that antioxidants are effective as stabilisers, there is no information about their effect on the texture of gels. By the other hand, Atlantic mackerel has been reported to be a poor gel forming species (Bakir et al., 1994b), therefore, the application of high pressure could be an alternative to improve gelation.

The aim of this study was to evaluate, by objective analysis, the textural characteristics of mackerel mince gels that had been fortified with omega-3 and rosemary extract. The processing method by which the gel is induced and the 
lipid oxidation/antioxidant effect in gel depending on treatment was also considered.

\section{MATERIAL AND METHODS}

Atlantic mackerel (Scomber scombrus) used in this study was caught off the Cantabrian coast in April and kept at $4{ }^{\circ} \mathrm{C}$ for about 24-48 h. Average size was $32.9 \pm 2.26 \mathrm{~cm}$ and average weight $440.45 \pm 124.78 \mathrm{~g}$.

$150 \mathrm{~kg}$ of fish were headed, gutted and washed. Skin and bones were removed with a deboning machine (Baader 694, Lübeck, Germany). The resulting mince (3 $\mathrm{mm}$ o.d.) was washed in a solution of $\mathrm{NaCl}(0.2 \%)$ at $0-3{ }^{\circ} \mathrm{C}$, proportion 3:1 (solution: minced muscle), first with constant stirring for 10 min then without stirring for another $10 \mathrm{~min}$. After draining, excess water was removed using a screw press (Baader 523, Lübeck, Germany). Sorbitol (4\%) and tripoly-phosphate (0.5\%) were added as cryoprotectants. The mince was immediately vacuum-packed in bags (Cryovac BB-1, Grace, Spain) and frozen in a plate-freezer (Sabroe SMC, Denmark). The bags were stored at $-80^{\circ} \mathrm{C}$ in a freezer cabinet (Revco ULT, Giralt, Revco Scientific, Inc., Asheville, N.C., USA) in order to minimize alteration during frozen storage up to gel preparation.

Soluble protein of mince in $5 \% \mathrm{NaCl}$ was performed according to Ironside and Love (1958). Proximate analyses were carried out according to AOAC (1975).

Gel preparation: Frozen mackerel mince was tempered in a chilled room and placed in a refrigerated vacuum homogeniser (Stephan UM5, Stephan u. Söhne GmbH \& Co., Germany). It was ground for $1 \mathrm{~min}$ at high speed. Sodium chloride $(2 \% \mathrm{w} / \mathrm{w})$ in gel (Panreac, Montplet \& Esteban S.A., Barcelona, Spain) was added and homogenised for $3 \mathrm{~min}$ at slow speed. Then rosemary extract $(\mathbf{R})$ or oil (0) was added with crushed ice to give the required final gel moisture (78 \%); in the formulation with oil added, the amount of water was substituted in part by the oil. The selected omega-3 fish oil (ROPUFA 30 Technologies, Derbyshire, DE) was added in a proportion of $2.5 \%$ to fortify the 
product while retaining acceptable sensory characteristics; the commercial oil already contained rosemary as an ingredient to stabilise the oil (16.5\% of docosahexaenoic acid (DHA)). The natural antioxidant rosemary (R) (Herbalox ${ }^{\mathrm{TM}}$ seasoning Type HT-O, Kalsec Kalamozoo, MI, USA) was added at the recommended level of usage to avoid a bitter taste $(0.075 \%)$. This is a patented rosemary oleoresin, which has been standardized with vegetable oil.

The homogenate was beaten slowly for 5 min under vacuum, keeping sample temperature below $10^{\circ} \mathrm{C}$.

Gel forming treatments. Batters were stuffed into flexible plastic casings (Krehalon Soplaril, Barcelona, Spain) of $40 \mu \mathrm{m}$ thickness and $3.5 \mathrm{~cm}$ diam. Highpressure treatments were performed in a high pressure pilot unit (ACB 665, Gec Alsthom, Nantes, France) where the temperature of the immersion medium was controlled via a thermocouple. The pressure was increased by $25 \mathrm{MPa} / \mathrm{s}$. The following treatments were applied: $300 \mathrm{MPa}, 25^{\circ} \mathrm{C}, 15 \mathrm{~min}(\mathbf{P})$ and with prior setting at atmospheric pressure $25^{\circ} \mathrm{C}, 2$ hours (SP); and heat treatment at atmospheric pressure with setting: $25^{\circ} \mathrm{C}, 2$ hours followed by $90^{\circ} \mathrm{C}, 50 \mathrm{~min}$ (ST). All the casings were immediately cooled with water at $0{ }^{\circ} \mathrm{C}$ and stored in a cold room at $4{ }^{\circ} \mathrm{C}$ for 18 hours before analysis. 
Rheological measurements.

Dynamic small strain studies of mince batter with $\mathrm{NaCl}$ were performed on a Bohlin CRS-10 rheometer rotary viscometer (Bohlin Instruments Ltd., Gloucestershire, U.K.) using a cone-plate geometry (cone angle $4^{\circ}$, gap $=1,50 \mathrm{~mm}$ ). Temperature ramps were implemented from $7^{\circ} \mathrm{C}$ to $85^{\circ} \mathrm{C}$, performed at a scan rate of $1^{\circ} \mathrm{C} / \mathrm{min}$, frequency $1 \mathrm{~Hz}$ and oscillating target strain $0.02 \mathrm{~mm}$. The elastic modulus ( $G$ ') was plotted as a function of temperature. The error in the reproducibility of the parameters considered in different determinations of a single sample was $6 \%$ or less.

Formed gels were removed from their casings, cut $(3.5 \mathrm{~cm}$ diameter, $3 \mathrm{~cm}$ height) and tempered at $22{ }^{\circ} \mathrm{C}$. Folding test resistance of a slice $(3.5 \mathrm{~cm}$ diameter and $3 \mathrm{~mm}$ high) folded over twice, score 1-5.

Puncture test was performed with a round-ended stainless steel plunger $(\varnothing=5$ $\mathrm{mm}$ ) at $10 \mathrm{~mm} / \mathrm{min}$ using a load-cell of $100 \mathrm{~N}$. Breaking deformation (mm), breaking force $(\mathrm{N})$ and work of penetration (N.mm) were measured.

Elasticity (\%) and Hardness $(\mathrm{N})$ were determined by a stress-relaxation test, with a compression to $30 \%$ and $1 \mathrm{~min}$ relaxation, at a deformation rate of $50 \mathrm{~mm} / \mathrm{min}$, using a cylindrical plunger $(\varnothing=58 \mathrm{~mm}$ ) adapted to a load-cell of $5 \mathrm{kN}$. Per cent relaxation was calculated as $\mathrm{YT}=100 \times(\mathrm{F} 0-\mathrm{F} 1) / \mathrm{F} 0$, where $\mathrm{F} 0$ is the force registered at the onset of relaxation immediately after sample compression (Hardness [N]) and $\mathrm{F} 1$ is the force registered after 1 min relaxation. Thus, 100-YT is taken as an index of elasticity and is expressed as per cent elasticity of the gel. At least four replications of all determinations were performed.

Gel protein solubilisation. Formed gels were solubilised in $0.6 \mathrm{M} \mathrm{NaCl}, 8 \mathrm{M}$ urea and $2 \% \beta$-mercaptoethanol, following the method indicated by Montero et al. (1997). Protein solubility was expressed as percent soluble protein with respect to total protein, determined previously by the Kjehldahl method. 
Scanning electron microscopy. Cubes of 2 to $3 \mathrm{~mm}$ were cut from inside the gels for microscopic examination. Samples were fixed in $2 \%$ glutaraldehyde in phosphate buffer $(\mathrm{pH}$ 7.3) and dehydrated in increasing series of acetone (from 40 to $100 \%$ ). They were then critical-point dried with $\mathrm{CO}_{2}$ as transition fluid in a dryer (Balzer CPD030, Liechtenstein) and mounted on copper sample holders, followed by sputter-coating with gold in a metallizer (Balzer SCD004). Samples were kept in a dryer until examination by scanning microscope (Jeol, JSM 6400, Japan) at 20 $\mathrm{kV}$. Micrographs of each gel were taken at 500 magnifications.

TBA index (thiobarbituric acid) was performed following the method of Vyncke (1970). Results were expressed as $\mu \mathrm{mol}$ malonaldehyde per $100 \mathrm{~g}$ of gel.

Statistical analysis. One-way analysis of variance was carried out using the SPSS computer program (SPSS Statistical Software, Inc.,Chicago, III. The difference of means between pairs was resolved by means of confidence intervals using a Tukey test . Level of significance was set for $P \leq 0.05$.

\section{RESULTS AND DISCUSSION}

\section{Compositional and functional characteristics of mince}

The mackerel mince was characterised by a proximate composition of $13.63 \%$ ( \pm $0.64)$ crude protein, $80.84 \%( \pm 0.56)$ moisture, $5.18 \%( \pm 0.83)$ crude fat and 0.35 $\%( \pm 0.05)$ ash content (analyses do not show $4.5 \%$ of added cryoprotectant).

Protein solubility in $5 \% \mathrm{NaCl}$ was $68.70 \%( \pm 3.11)$, which denoted a relatively low degree of myofibrillar protein denaturation after washing and mince preparation. In a previous study, a sardine mince having $62.61 \%$ protein solubility was judged as high-quality mince for gelling purpose, in contrast to a low-quality mince with 49.75\% soluble protein (Gómez-Guillén et al., 1996).

Thermal gelation profiles of mince, at a heating rate of $1{ }^{\circ} \mathrm{C} / \mathrm{min}$, with and without overnight setting at $5^{\circ} \mathrm{C}$, are shown in Fig. 1 . Both curves presented a fall in G' values at around $35-40^{\circ} \mathrm{C}$. The overnight set batter showed a sharp increase in G' 
from $45^{\circ} \mathrm{C}$ upwards, reaching a maximum at $65^{\circ} \mathrm{C}$. In contrast, $\mathrm{G}^{\prime}$ did not recover in the batter without setting, denoting a very low gelling capacity. This behaviour was quite different than in other fatty species, such as sardine (Gómez-Guillén et al., 1997), which showed a typical setting at $35-37^{\circ} \mathrm{C}$. Similarly, Tsukamasa and Shimizu (1990) found a meat sol of Pacific mackerel hardly to set over the temperature range $30-40^{\circ} \mathrm{C}$, in opposite to what happened with a sardine meat sol. As can be observed in Fig. 1, in the case of mackerel mince, a slight setting took place in the range of $15-25^{\circ} \mathrm{C}$, more pronounced in the batter without overnight maturation.

Similar thermal profiles have been reported for squid gelation, largely attributing poor gelling properties to proteolytic activity (Gómez-Guillén et al., 2001). The lower values at $15-25^{\circ} \mathrm{C}$ in the set batter could be the result of autolytic activity for several hours, however, the posterior rise in G' suggested a certain degree of protease inactivation during heating, favouring thermal gelation.

The poor gel forming capacity of the mince was confirmed by preparing a gel by heating at $90^{\circ} \mathrm{C}$, with a previous setting at $25^{\circ} \mathrm{C}$ during 2 hours, where the folding test scored "3" in a 5-point grade system. Poor gelling properties of Atlantic mackerel have been reported previously (Bakir et al., 1994b).

Instead of heating, a high-pressure treatment at $300 \mathrm{MPa}$ with and without previous setting at $25^{\circ} \mathrm{C}$ improved gelling ability considerably by achieving gels with maximum folding test score ("5").

\section{Rheological properties of fortified gels}

Fig. 2 represents the results of a puncture test carried out on heat- (ST) and pressure-induced $(P)$ gels, fortified with omega-3 fatty acids or with rosemary extract. In addition, a setting step at $25^{\circ} \mathrm{C}$ prior to pressurisation was also applied (SP), in order to compare both types of gelation.

All gels induced by high pressure (P and SP) presented almost twice the breaking deformation of the thermal gels. Values were slightly higher in gels with setting prior to high-pressure treatment. There were differences $(p \leq 0.05)$ depending on 
the ingredient added only in set and pressure-induced gels (SP), deformation being higher in the lots with rosemary extract than with omega-3.

Breaking force was significantly increased in pressure-induced gels made with previous setting (SP), especially when rosemary extract was included. However, gels made without prior setting showed slightly lower breaking force than the heatinduced gels. Breaking deformation and breaking strength both influenced the work of penetration. This was practically double for gels induced by setting and pressure than for the others. Only with this treatment there was evidence of a significant $(p \leq 0.05)$ tendency for the work of penetration to increase with rosemary extract, and by the other hand, to decrease with omega-3.

A compression-relaxation test was performed to further rheological characterisation of gels. Elasticity after $30 \%$ compression (Fig 3) was significantly increased (around 10\%) in the lots induced by high pressure (P and SP), whereas hardness was the opposite, i.e. considerably lower in pressure-induced gels, especially in those without prior setting. In this connection, Fernández-Martín et al. (2000) reported a decreased hardness in pressurised pork meat batters to onefifth.

Regarding heat-induced gels, lots with added omega-3 presented increased $(P \leq 0.05)$ hardness with respect to the control. No other significant differences were found depending on the ingredient added. In this sense, Pérez-Mateos et al. (2001) reported no influence on the torsion test of thermal gels by the addition of different oil preparations or natural antioxidants (rosemary or green tea extract).

\section{Structural properties of fortified gels}

In Fig. 4 , the micrograph of the gels induced by heat treatment (ST) showed a typical reticular structure in the control gel (with no additives) with a few zones having a more compact matrix. The corresponding gel with rosemary showed similar appearance, with denser reticular structure and with the presence of several little cavities where globules with the lipophylic antioxidant, could have 
been allocated. The addition of omega- 3 modified the behaviour in a similar way to rosemary extract, but oil globules in the matrix were much larger, and this could lead to increased hardness.

The control gels induced by high pressure treatment $(P)$ showed practical absence of true reticular structure, and the matrix was considerably denser than in the corresponding gel thermally induced. The pressure-induced gels containing rosemary extract or omega-3 showed no evidence of reticular formations given the extremely high degree of gel matrix compactness. The main difference between both types of gel led in the presence of numerous small cavities in the omega-3 containing gel, which in fact were of smaller size than in the corresponding heatinduced gel. A similar behaviour was reported by Fernández-Martín et al. (2000) in pressurised pork meat batters with added potato starch.

A setting step at $25^{\circ} \mathrm{C}$ prior to pressure treatment resulted in an even more compacted matrix in the gel without additives. Visually, the micrographs of gels containing rosemary extract and omega-3 are quite similar to those of pressureinduced gels without setting.

The major differences are therefore attributable to the treatment rather than to the presence of the ingredient, although each ingredient, especially omega-3, confers a particular characteristic. Previous works with high pressure reported also that pressure effects clearly predominated over ingredient effects (Fernández et al., 1998; Pérez-Mateos and Montero, 2001). The disappearance of the reticular network structure as a consequence of the pressure treatment seems to be a major factor for decreased hardness in pressured gels; however, the more compacted matrix acts in benefit of the elastic behaviour, both measured by the compression-relaxation test. In contrast, the increased breaking force and work of penetration in all pressure-induced gels, with previous setting, could not be directly attributed to changes at the microstructure level, at least when rosemary extract or omega-3 were added.

\section{Protein solubility in fortified gels}


Certain kind of bonds, such as hydrogen and disulphide bonds, as well as hydrophobic interactions, may be disrupted by solubilising the gels with a solution containing $0.6 \mathrm{M} \mathrm{NaCl}, 8 \mathrm{M}$ urea and $2 \% \beta$-mercaptoethanol (Matsumoto, 1980). The precipitate remaining after centrifugation is, therefore, the result of larger polymers aggregated by stronger covalent bonding.

As shown in Fig. 5, the soluble fraction of the sample without additives was higher in the pressure- than in the heat-induced gel, whereas in the pressure-induced gel with prior setting, intermediate values were obtained. This finding suggest that heat-induced gels presented large amounts of covalent bonds, which could not be disrupted by the solubilising agent. The effect of the setting step at $25^{\circ} \mathrm{C}$, which has been reported to involve non-disulphide cross-linking of protein due to the action of endogenous transglutaminase (TGase) activity, may be largely responsible for this behaviour (Kamath et al., 1992; Nowsad et al., 1996). However, given the difference between ST and SP treatments, such covalent bonding might also occur at higher temperature. By the other hand, Montero et al. (1997) reported increased hydrophobic interactions in sardine mince gel obtained by high-pressure treatment.

Gels containing rosemary extract showed an increase in the solubilised fraction, in comparison to the gel with no additives, only when thermal treatment (ST) was applied. In the case of gel with added omega-3, the soluble fraction was even more increased. This may be related to the number and larger size of oil inclusions in omega-3 containing gels, as observed in the microscopic study. Given that this effect was also very evident in the corresponding pressure-induced gel with prior setting, this suggest that the lipid-protein interaction may interfere with the covalent bonds attributed to TGase activity formed during the setting step. In the case of gels containing rosemary extract, the small inclusion globules disappeared completely when pressure was applied, and this could explain the lack of differences with respect to the sample without additives.

\section{Lipids stability and antioxidant activity}


Lipid oxidation in gels frozen stored during three months was evaluated using the thiobarbituric acid (TBA) index (Fig. 6). Values obtained in heat-induced gels were very low, and coincided with those reported previously in frozen sardine mince gels stored for a similar period (Martí et al., 1997).

High-pressure treatment activated lipid oxidation in the gel with no additives, being significantly higher when pressure was combined with prior moderate heating (S$P)$; this could be attributed to both chemical and enzymatic lipid reactions with increased free hydroxyl radicals. All pressure-induced gels containing rosemary extract or omega-3 showed significantly $(\mathrm{p} \leq 0.05)$ lower TBA values than in the corresponding gels without additives, which denoted a considerable antioxidant capacity. This is agreement with other works that reported antioxidant properties of rosemary (Wada \& Fang, 1992; Boyd et al., 1993). In the case of gels with omega3 , the antioxidant already included in the commercial preparation seemed to be active enough to prevent oxidation of muscle and non-muscle lipids.

\section{Conclusions}

The poor gelling properties of mackerel mince could be improved by a combination of moderate heating at $25^{\circ} \mathrm{C}$ and subsequent pressurisation at 300 $\mathrm{MPa}$. Gel fortifying ingredients used did not hinder gel formation, but they may produce slight alterations in rheological characteristics, which need to be considered when developing products. As high pressure induced some lipid oxidation, it is convenient to incorporate antioxidants.

\section{Acknowledgements}

This research was supported by the Spanish Comisión Interministerial de Ciencia y Tecnología under projects ALI 99-1105 and ALI AGL2000-1497.

\section{References}

Angelo, S.T., Crippen, K.L., Duputy, H.P. \& James, J.R. (1990).Chemical and sensory studies of antioxidant-treated beef. Journal of Food Science, 55(6), 1501-1505, 1539. 
AOAC. 1975. Official Methods of Analysis, $12^{\text {th }}$ ed. AOAC: Arlington, VA

Bakir, H.M., Hultin, H.O. \& Kelleher, S.D. (1994a). Gelation properties of fatty fish processed with or without added sodium chloride, cryoprotectants and antioxidants. Food Research International, 27(5), 443-449.

Bakir, H.M., Hultin, H.O. \& Kelleher, S.D. (1994b). Some properties of fish gels made from several northwest Atlantic species in the presence of high and low salt. Journal of Food Processing and Preservation, 18(2), 103-117.

Barbut S, Josephson DB \& Maurer AJ (1985). Antioxidant properties of rosemary oleoresin in turkey sausage. J Food Sci 50 (5): 1356-1359,1363.

Boyd, L.C., Green, D.P., Giesbrecht, F.B. \& King, M.F. (1993). Inhibition of oxidative rancidity in frozen cooked fish flakes by tert-butylhydroquinone and rosemary extract. Journal of the Science of Food and Agriculture 61, 87-93.

Buttler, A.J. \& Larick, D.K. (1993). Effect of antioxidant on the sensory characteristics and Storage Stability of Aseptically processed Low-fat beef gels. Meat Science, 35, 355-369.

Chastain, M.F., Huffman, D.L., Hsieh, W.H. \& Cordray, J.C. (1982). Antioxidants in restructured beef/pork steaks. Journal of Food Science, 47(6),1779-1782.

Crackel, R.L., Gray, J.L., Booren, A.M., Pearson, A.M. \& Buckley, D.J. (1988). Effect of antioxidant on lipid stability in restructured beef steaks. Journal of Food Science, 53(2), 656-657.

Duxbury, D.D. (1989). Decolorized, deflavorized rosemary extract antioxidant properties retard oxidative rancidity. Food processing, 50, 62-64. 
Fernandez, P., Cofrades, S., Solas, M.T., Carballo, J. \& Colmenero, F.J. (1998). High pressure-cooking of chicken meat batters with starch, egg white, and iota carrageenan. Journal of Food Science, 63(2), 267-27.

Fernández-Martín, F., Gueraa, M.A., López, E., Solas, M.T., Carballo, J. \& Jiménez-Colmenero, F. (2000). Characteristics of pressurised pork meat batters as affected by addition of plasma proteins, apple fibre and potato starch. Journal of the Science of Food and Agriculture, 80, 1230-1236.

Gómez-Guillén M.C. \& Montero, P. (1996). Thermal aggregation of sardine muscle proteins during processing. Journal of Agricultural and Food Chemistry, 44, 36253630 .

Gómez-Guillén, M.C., Borderías, A.J. \& Montero, P. (1996). Rheological properties of gels made from high- and low-quality sardine (Sardina pilchardus) mince with added nonmuscle proteins. Journal of Agricultural and Food Chemistry, 44,746750.

Gómez-Guillén, M.C., Borderías, A.J. \& Montero, P. (1996). Thermal gelation properties of two different composition sardine (Sardina pilchardus) muscles with addition of non-muscle proteins and hydrocolloids. Food Chemistry, 58(1), 81-87.

Gómez-Guillén, M.C., Hurtado, J.L. \& Montero, P. (2001). Autolysis and protease inhibition effects on dynamic viscoelastic properties during thermal gelation of squid muscle. In press.

Ironside, J.I.M. \& Love, R.M. (1958). Studies on protein denaturation in frozen fish. I. Biological factors influencing the amounts of soluble and insoluble protein present in the muscle of the north Sea Cod. Journal Science Agricultural, 9, 597617. 
Kamath, G.G., Lanier, T.C., Foegeding, E.A. \& Hamann, D.D.. (1992). Nondisulfide covalent cross-linking of myosin heavy chain in 'setting' of Alaska pollock and Atlantic croaker surimi. Journal of Food Biochemistry 16(3), 151-172.

Liu, H.F., Booren, A.M., Gray, J.I. \& Crackel, R.L. (1992). Antioxidant efficacy of oleoresin rosemary and sodium tripolyphosphate in restructured pork steaks. Journal of Food Science, 57(4), 803-806.

Lai, S., Gray, J.L., Smith, D.M., Booren, A.M., Crackel, R.L. \& Buckley, D.L. (1991). Effects of oleoresin rosemary, tertiary butylhydroquinone, and sodium tripolyphosphate on development of oxidative rancidity in restructured chicken nuggets. Journal of Food Science, 56(3), 616-620.

Martí de Castro, M.A., Gómez-Guillén, M.C. \& Montero, P. (1997). Influence of frozen storage on textural properties of sardine (Sardina pilchardus) mince gels. Food Chemistry, 60(1), 85-93.

Matsumoto, J.J. (1980). Chemical deterioration of muscle proteins during frozen storage. In Chemical deterioration of proteins, Whitaker, J.R., Fujimaki, M., Eds., ACS Symposium Series 123, American Chemical Society, Washington, DC, pp. 95-124.

Messens, W., Van Cam, J. \& Huyghebaert, A.(1997). The use of high pressure to modify the functionality of food proteins. Trends in Food Science and Technology, 8,107-112.

Montero, P., Gómez-Guillén, M.C. \& Borderías, J. (1996). Influence of subspecies, season and stabilization procedures in gel-forming ability of frozen minced muscle of sardine (Sardine pilchardus). Food Science and Technology, 2,111-122. 
Montero, P., Peréz-Mateos, M. \& Solas, M. (1997). Comparation of different gelation methods using washed sardine (Sardina pilchardus L.) mince: effect of temperature and pressure. Journal Agriculture and Food Chemistry, 45, 46124618.

Nowsad, A.A., Katoh, E., Kanoh, S. \& Niwa, E. (1996). Contribution of transglutaminase to the setting of fish pastes at various temperatures. Fisheries Science, 62(1), 94-97.

Pardo, M.V. (1999). Estudio de la funcionalidad y caracteristicas fisicoquimicas de las proteínas del músclo de sardina (Sardina pilchardus L.) durante su conservación en estado congelado. Gelificación mediante la utilización de hidrocoloides y proteínas no musculares. Doctoral Tesis. Ed. Universidad Complutense. Madrid. Spain.

Pérez-Mateos, M. \& Montero, P. (2001). Effects of hydrocolloids and high-pressureheating processing on minced fish gels

. European Food Research and Technology 2001 (213)7: faltan paginas.

Pérez-Mateos, M., Boyd, L., Allen, J.C. \& Lanier, T.C. (2001). Omega-3 fortification of surimi seafood. 46 th Atlantic Fisheries Technology Conference (AFT) 26-29 August. Rimouski, Québec, Canada.

Stoick, S.M., Gray, J.I., Booren, A.M. \& Buckley, D.J. (1991). Oxidative stability of restructured beef steaks processed with oleoresin rosemary, tertiary butylhydroquinone, and sodium tripolyphosphate. Journal Food Science, 56(3), 597- 600 .

Tsukamasa,Y. \& Shimizu,Y. (1990). Setting property of sardine and Pacific mackerel meat. Nippon Suisan Gakkaishi, 56 (7), 1105-1112. 
Vyncke, W. (1970). Direct determination of the thiobarbituric acid value in trichloroacetic acid extract of fish as a measure of oxidative rancidity. Fette Seinfen Anstrichm 72:1084-1087.

Wada, S. \& Fang, X. (1992). The synergistic antioxidant effect of rosemary extract and $\alpha$-tocopherol in sardine oil model system and frozen-crushed fish meat. Journal of Food Processing and Preservation, 16, 263-274. 


\section{Legend to figures}

Figure 1.- Thermal gelation profile, in terms of elastic modulus ( $\left.G^{\prime}\right)$, of fish mince batter, without and with overnight setting at $5^{\circ} \mathrm{C}$.

Figure 2.- Breaking deformation, breaking force and work of penetration of gels.

ST: $25^{\circ} \mathrm{C}, 2 \mathrm{~h} / 90^{\circ} \mathrm{C}, 50 \mathrm{~min}$; P: $300 \mathrm{MPa}, 15 \mathrm{~min}, 25^{\circ} \mathrm{C}$; SP: $25^{\circ} \mathrm{C}, 2 \mathrm{~h} / 300 \mathrm{MPa}, 15 \mathrm{~min}$, $25^{\circ} \mathrm{C}$.

C: control; R:rosemary; O:omega-3.

Figure 3.- Elasticity and hardness of gels.

ST: $25^{\circ} \mathrm{C}, 2 \mathrm{~h} / 90^{\circ} \mathrm{C}, 50 \mathrm{~min}, \mathrm{P}: 300 \mathrm{MPa}, 15 \mathrm{~min}, 25^{\circ} \mathrm{C}$; SP: $25^{\circ} \mathrm{C}, 2 \mathrm{~h} / 300 \mathrm{MPa}, 15 \mathrm{~min}$, $25^{\circ} \mathrm{C}$.

C: control; R:rosemary; O:omega-3.

Figure 4.- Scanning electron micrographs (500x) of gels. Cavities are marked by white arrows.

ST: $25^{\circ} \mathrm{C}, 2 \mathrm{~h} / 90^{\circ} \mathrm{C}, 50 \mathrm{~min}, \mathrm{P}: 300 \mathrm{MPa}, 15 \mathrm{~min}, 25^{\circ} \mathrm{C}$; SP: $25^{\circ} \mathrm{C}, 2 \mathrm{~h} / 300 \mathrm{MPa}, 15 \mathrm{~min}$, $25^{\circ} \mathrm{C}$.

C:control, R:rosemary extract, O:omega-3.

Figure 5.- Soluble protein of gels extracted using $0.6 \mathrm{M} \mathrm{NaCl}+8 \mathrm{M}$ urea+ $0.5 \mathrm{M} \beta$ mercaptoethanol.

ST: $25^{\circ} \mathrm{C}, 2 \mathrm{~h} / 90^{\circ} \mathrm{C}, 50 \mathrm{~min}, \mathrm{P}: 300 \mathrm{MPa}, 15 \mathrm{~min}, 25^{\circ} \mathrm{C}$; SP: $25^{\circ} \mathrm{C}, 2 \mathrm{~h} / 300 \mathrm{MPa}, 15 \mathrm{~min}$, $25^{\circ} \mathrm{C}$.

C:control, R:rosemary extract, O:omega-3.

Figure 6.- TBA index ( $\mu \mathrm{mol}$ malonaldehyde/100 $\mathrm{g}$ gel) of gels after 3 months of frozen storage at $-20^{\circ} \mathrm{C}$.

ST: $25^{\circ} \mathrm{C}, 2 \mathrm{~h} / 90^{\circ} \mathrm{C}, 50 \mathrm{~min}, \mathrm{P}: 300 \mathrm{MPa}, 15 \mathrm{~min}, 25^{\circ} \mathrm{C}$; SP: $25^{\circ} \mathrm{C}, 2 \mathrm{~h} / 300 \mathrm{MPa}, 15 \mathrm{~min}$, $25^{\circ} \mathrm{C}$.

C:control, R:rosemary extract, O:omega-3. 


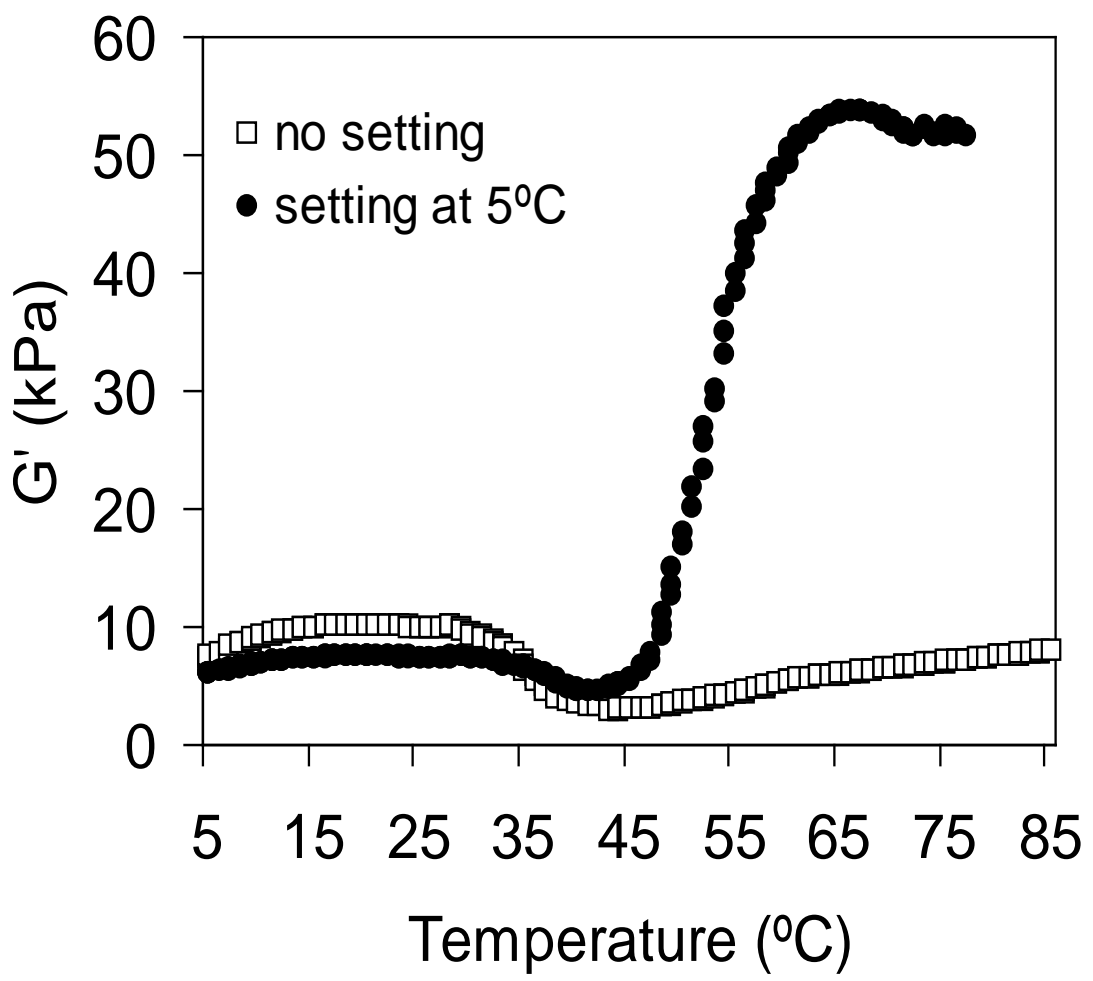



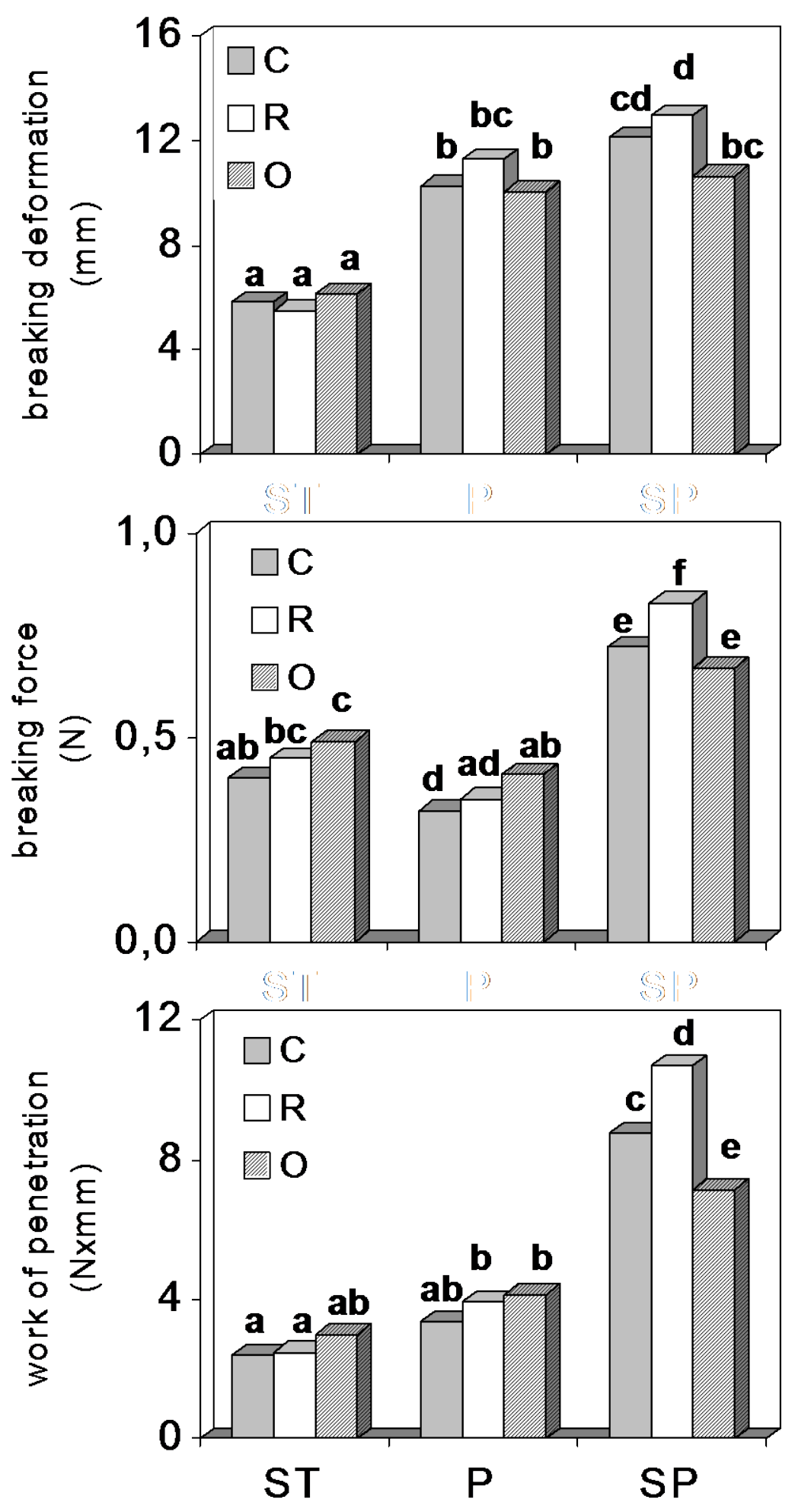


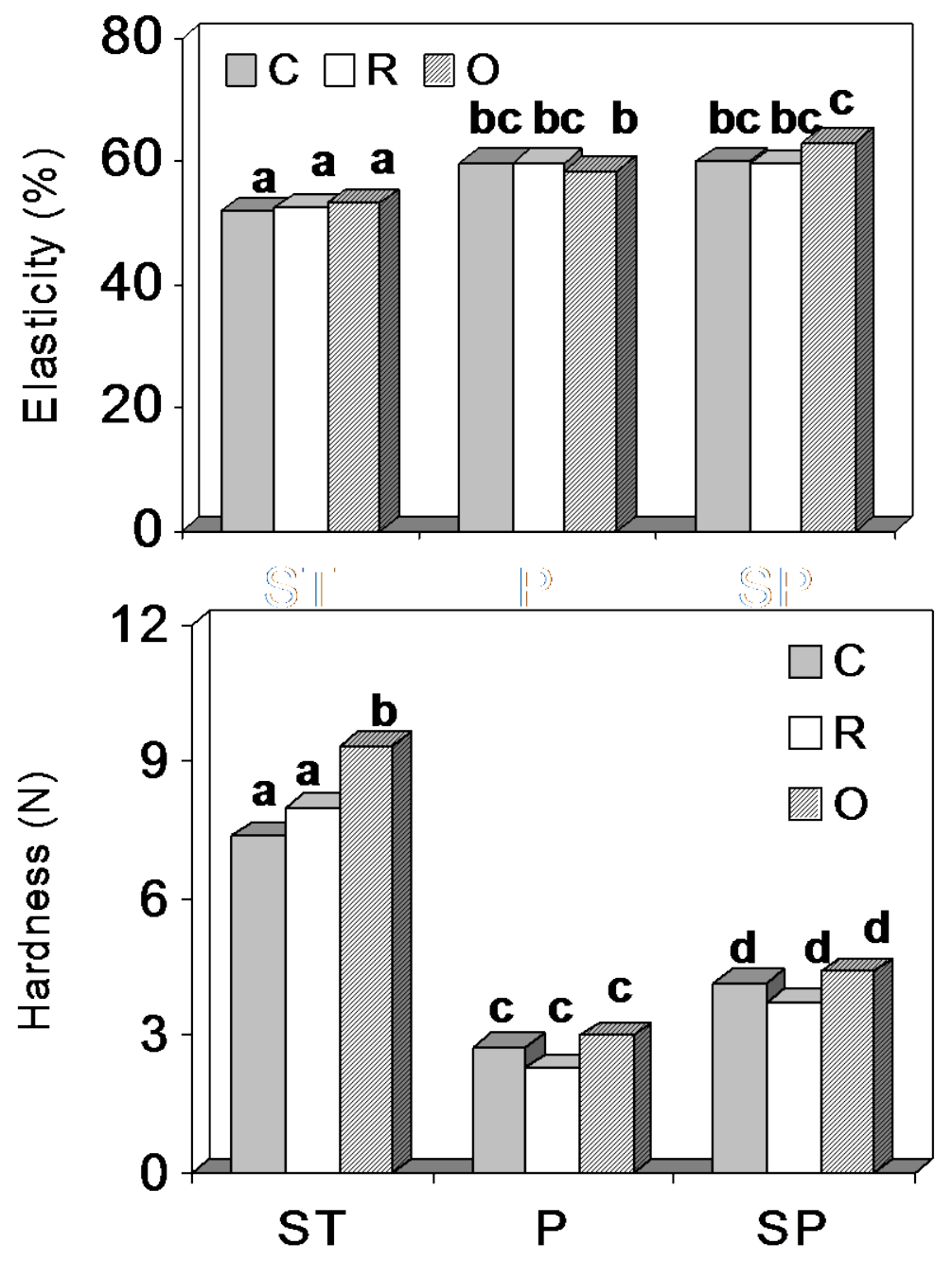

Food Chem. 2002;79(1):1-8 



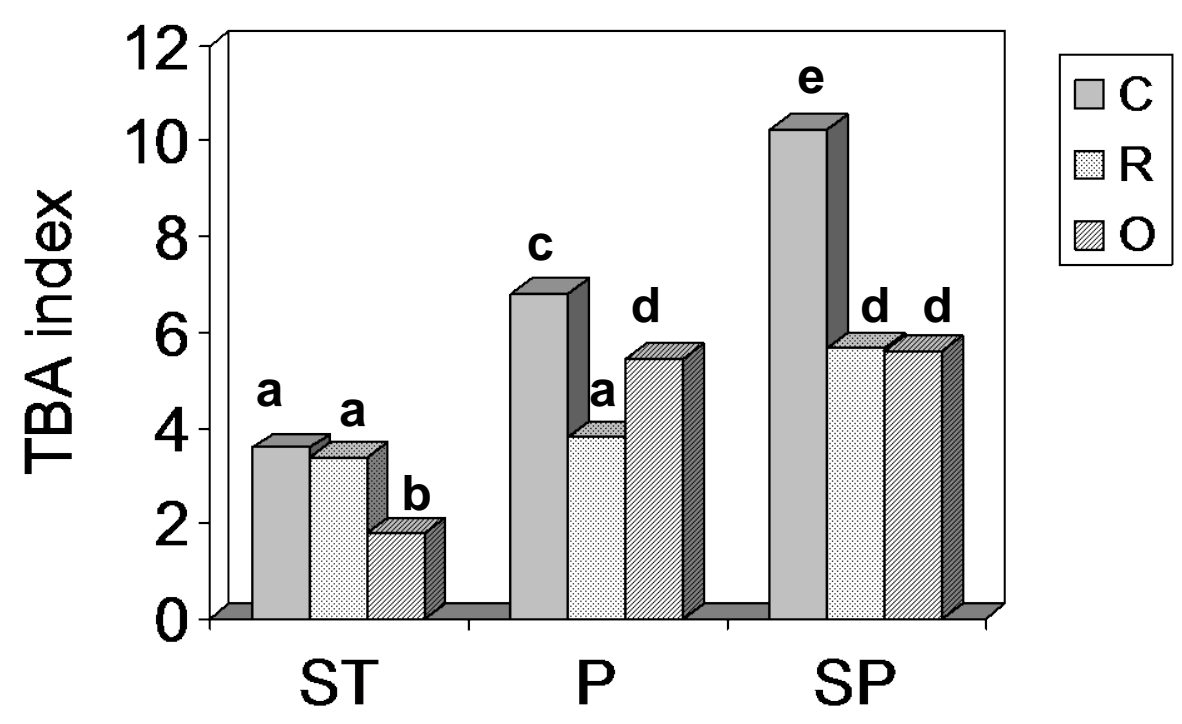

Food Chem. 2002;79(1):1-8 